\title{
The structure of dominance hierarchies in the primitively eusocial wasp Ropalidia marginata
}

\author{
A. Sumana ${ }^{1}$ and R. Gadagkar ${ }^{1,2,3}$ \\ ${ }^{1}$ Centre for Ecological Sciences, Indian Institute of Science, Bangalore 560 012, India \\ ${ }^{2}$ Evolutionary and Organismal Biology Unit, Jawaharlal Nehru Centre for Advanced \\ Scientific Research, Jakkur, Bangalore 560 064, India
}

Received 19 September 2000, accepted 13 March 2001

\begin{abstract}
In queenright colonies of the old world tropical primitively eusocial polistine wasp, Ropalidia marginata, queens are behaviourally docile and subordinate individuals. Yet, they are completely successful in suppressing reproduction by all nestmates. Here we show that dominance hierarchies in queenright colonies are never significantly linear but, in the queen determination stage, when new queens use overt physical aggression to establish their status, dominance hierarchies among the same individuals are significantly linear. This striking difference in the structure of dominance hierarchies in queenright colonies as compared to the queen determination stage, is consistent with the previously postulated hypothesis that, while dominance behaviour functions to regulate worker reproduction in the queen determination stage, the same behaviours are used by the workers to regulate each others' foraging in queenright colonies.
\end{abstract}

KEY WORDS: Ropalidia marginata, social wasp, dominance hierarchy, linearity of dominance hierarchy, reproductive conflicts, regulation of foraging.

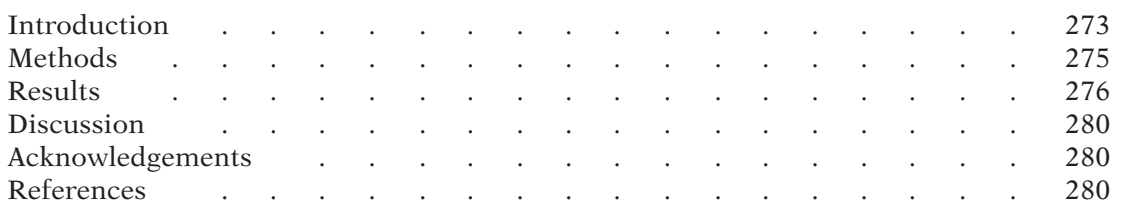

\section{INTRODUCTION}

Ropalidia marginata is an old world, tropical, primitively eusocial, polistine wasp abundantly distributed in peninsular India. New nests may be initiated by one or by several female wasps. In single foundress nests, the lone foundress lays eggs

${ }^{3}$ Address for correspondence: Phone (off.): (91-80) 3601429; Fax: (91-80) 3602121; Phone (res.): (91-80) 3601758; (E-mail: ragh@ces.iisc.ernet.in); (URL: http://ces.iisc.ernet.in/hpg/ragh). 
and also performs all other tasks such as nest building, foraging and brood care, at least until the eclosion of the first set of adult female offspring. In multiple foundress nests on the other hand, a striking division of labour is immediately established: one individual assumes the role of the sole egg layer (queen) and the remaining individuals (workers) perform all non-reproductive tasks such as nest building, foraging, brood care etc. (GADAGKAR 1991, 2001). In most primitively eusocial species studied, the queen is a behaviourally dominant individual and uses physical aggression and her physical interactions with nestmates to suppress their reproduction as well as to regulate their non-reproductive activities such as foraging (WESTEberhard 1969; Jeanne 1972; Reeve \& Gamboa 1983, 1987; Gamboa et al. 1990; REEVE 1991). Relative to most other primitively eusocial wasps studied so far, the queens of $R$. marginata are quite unusual; they are strikingly docile and behaviourally subordinate. Multivariate statistical analysis of time-activity budgets of individually identified wasps permits the classification of all wasps in a colony into three rather distinct behavioural castes which have been named Sitters, Fighters and Foragers (GADAGKAR \& JosHI 1983, GADAGKAR 2001). In almost all colonies studied so far, queens get classified as Sitters (CHANDRASHEKARA \& GADAGKAR 1991, GADAGKAR 2001).

Members of a colony frequently indulge in dominance-subordinate interactions where one individual can be unambiguously designated as dominant and the other as subordinate. On the basis of such interactions a dominance hierarchy can be constructed. In most colonies studied, queens are not located at the top of such behavioural hierarchies. Instead they are somewhere in the middle or at the bottom or may even completely fail to participate in dominance-subordinate interactions with their nestmates (CHANDRASHEKARA \& GADAGKAR 1992, GADAGKAR 2001). In spite of their docile and behaviourally subordinate character, queens of $R$. marginata are completely successful in suppressing reproduction by their nestmates, all colonies observed so far have only one egg layer at any given time. We have therefore speculated that $R$. marginata queens probably use a pheromone rather than overt physical dominance to suppress/regulate reproduction by their nestmates (PREMNATH et al. 1996, for a review see GADAGKAR 2001).

In striking contrast to such behaviour of queens in queenright colonies, the very same queens of $R$. marginata are extremely active and behaviourally dominant at the time that they first establish themselves as the queen of a colony (queen determination stage). Such extremely aggressive behaviour can be seen, when a new colony is founded, when a queen is naturally replaced and when queens are experimentally removed. During these periods, queens of $R$. marginata are always at the top of the behavioural dominance hierarchies of their colonies. Their level of aggression then drops gradually so that after a week or so they become behaviourally indistinguishable from queens of queenright colonies (PREMNATH et al. 1996). All this raises the question of the function of dominance-subordinate interactions in queenright colonies. Based on experiments involving removal of the queen and a study of how non-reproductive activities of workers are regulated, we have speculated previously that dominance-subordinate interactions in queenright colonies may function as a system of signals that workers use to regulate each others activities, especially foraging (PREMNATH et al. 1995, GADAGKAR 2001).

Although primitively eusocial wasps featured very early in studies of dominance hierarchies in animal societies (PARDI 1948) and the functional significance of dominance is well understood, social insects have lagged behind in studies concerning the structure of their dominance hierarchies (but see KasuYA 1995, TINDO \& DEJEAN 2000). One aspect of the structure of dominance hierarchies that has 
received considerable theoretical attention, is linearity. In a group of three animals $\mathrm{A}, \mathrm{B} \& \mathrm{C}$, if $\mathrm{A}$ is dominant over $\mathrm{B}, \mathrm{B}$ is dominant over $\mathrm{C}$ and $\mathrm{A}$ is also dominant over $\mathrm{C}$, such a relationship is termed transitive. On the other hand, if $\mathrm{A}$ is dominant over $\mathrm{B}, \mathrm{B}$ is dominant over $\mathrm{C}$ and $\mathrm{C}$ is dominant over $\mathrm{A}$, such a relationship is termed circular. A completely linear hierarchy is one in which all triads are transitive. LANDAU (1951) developed an index of linearity $h$, whose values range from 0.0-1.0. Since completely linear hierarchies are rare, this index has been used with an arbitrary cutoff of 0.9, above which a hierarchy is said to be linear (CHASE 1974, BEKOFF 1977, LEHNER 1996). APPLEBY (1983) explicitly incorporated a procedure to determine if the observed level of linearity could have been obtained by chance alone in a set of random interactions. DE VRIES (1995) has since developed an improved measure of linearity $h$ ', based on LANDAU's original $h$. This new index satisfactorily accounts for unknown and tied relationships in the dominance-subordinate matrix.

In the context of $R$. marginata we therefore considered it potentially interesting to determine the degree of linearity of the dominance hierarchies in queenright colonies (where we have previously postulated that the function of dominance hierarchies is unrelated to reproductive conflicts) and in the queen determination stage (where we have previously postulated that dominance hierarchies function in regulating reproductive conflicts). In this study we therefore measured the linearity of dominance hierarchies in $R$. marginata in queenright colonies as well in those from which the queens were removed.

\section{METHODS}

All observations/experiments were carried out on post-emergence nests of $R$. marginata (Lep.) (Hymenoptera Vespidae) maintained in the Vespiary at the Centre for Ecological Sciences, Indian Institute of Science, Bangalore. The Vespiary is a room measuring $9.3 \times 6 \times 4.8$ $\mathrm{m}$, covered with a wire mesh of dimensions $0.75 \times 0.75 \mathrm{~cm}$, which prevents the major predator Vespa tropica, from entering but allows $R$. marginata to fly in and out freely. $R$. marginata nests were located in various nesting sites in Bangalore $\left(13^{\circ} 00^{\prime} \mathrm{N}, 77^{\circ} 32^{\prime} \mathrm{E}\right)$, Mysore $\left(12^{\circ} 25^{\prime} \mathrm{N}\right.$, $\left.76^{\circ} 50^{\prime} \mathrm{E}\right)$ and Mudumalai $\left(11^{\circ} 34^{\prime} \mathrm{N}, 76^{\circ} 38^{\prime} \mathrm{E}\right)$, and transplanted to the Vespiary. In a few days after such transplantation, the nests establish normal social organisation and foraging activities. These nests were used for all observations/experiments. Wasps from these nests, it must be noted, forage from natural sources and are free to leave their nests or join other nests. All individuals in each colony were uniquely marked with small spots of quick drying paints of different colours.

As reported before (GADAGKar \& JoShi 1983, GADAGKAR 2001), dominance behaviours shown by $R$. marginata wasps consisted of aggressive biting, attack, being offered liquid, chase, crash, hold another individual in mouth, nibble, peck and sit on another individual. Their obvious counterparts such as being aggressively bitten, being attacked, offering liquid etc. were designated as subordinate behaviours. In this study the sum of all the dominant behaviours listed above was used to compute the frequency of dominance behaviour per hour, for each individual. Similarly the sum of all the subordinate behaviours, as indicated above, was used to compute the frequency of subordinate behaviour per hour for each individual.

\section{Experiment 1}

Twelve post-emergence nests were studied between August 1997 and December 1998. Each behavioural observation session lasted for $5 \mathrm{~min}$ and was followed by a $1 \mathrm{~min}$ break before the beginning of the next session. Observations were of two kinds: instantaneous 
scans, to record the behavioural state of each individual and "all occurrences" sessions where every performance of a set of selected behaviours by every individual was recorded. The scans and all occurrence sessions were randomly intermingled. Such observations were made for 5 $\mathrm{hr}$ each day in two separate blocks of $2 \mathrm{hr} 30 \mathrm{~min}$ each. Thus one "wasp day" lasting from 08:00 a.m. to 06:00 p.m. was covered uniformly over a 2 day period. These observations were conducted for each nest over 6 consecutive days, yielding $30 \mathrm{hr}$ of data with 96 scans and 204 all occurrence sessions per nest. The main focus during the all occurrence sessions was on dominance-subordinate interactions, although other kinds of interactions were also recorded.

\section{Experiment 2}

Twelve other post-emergence nests of $R$. marginata were studied between February and July 2000, as mentioned above, but except as noted below. Here each nest was observed on day 1 in its unmanipulated state. Before the beginning of observations on day 2 , the queen was removed and placed in a separate cage. Thus observations were made on day 2 in the absence of the queen. At the end of day 2, the queen was returned and observations were made on day 3 in the presence of the returned queen. Eight hours of observations were carried out on each of the 3 consecutive days, by the same observer, between 08:00 a.m. and 06:00 p.m. (in 3 sessions of 3, 3, and $2 \mathrm{hr}$ each), yielding $24 \mathrm{hr}$ of data, with 20 scans and 60 All Occurrence sessions per day.

\section{Data analysis}

MatMan version 1.0 for Windows was used to estimate linearity; after performing 10,000 simulations, a hierarchy was considered significantly linear if the right-tailed probability was less than or equal to 0.05 (DE VRIES 1995). Dominance hierarchies were constructed using an index of dominance (PREMnath et al. 1990), which in turn is a modified form of an index of fighting success developed for Red Deer (CLUTTON-BRock et al. 1979). The index of dominance is calculated for each individual by using the expression:

$$
D=\frac{\sum_{i=1}^{n} B_{i}+\sum_{j=1}^{m} \sum_{i=1}^{n} b_{j i}+1}{\sum_{i=1}^{n} L_{i}+\sum_{j=1}^{p} \sum_{i=1}^{n} l_{j i}+1}
$$

where $n$ is the number of individuals in the colony, $\Sigma B_{i}$ is the rate at which the subject shows dominance behavior towards colony members and $\Sigma b_{i i}$ is the sum of the rates at which all individuals dominated by the subject in turn show dominance behavior towards colony members; 1 to $m$ are thus individuals towards whom the subject shows dominance. Similarly, $\Sigma L_{i}$ is the rate at which the subject shows subordinate behavior towards colony members. $\Sigma I_{j i}$ is the sum of the rates at which those individuals towards whom the subject shows subordinate behavior, in turn show subordinate behavior towards other colony members; 1 to $p$ are thus the individuals towards whom the subject shows subordinate behavior. Individuals were then ordered in descending order of their values of dominance index. The individual with the highest value was assigned rank 1 and the remaining individuals were assigned consecutively increasing ranks. Other statistical comparisons were by a two-tailed G-test.

\section{RESULTS}

A typical dominance-subordinate network of interactions observed in one of the nests in experiment 1 is shown in Fig. 1A. As can be seen from the figure, these 


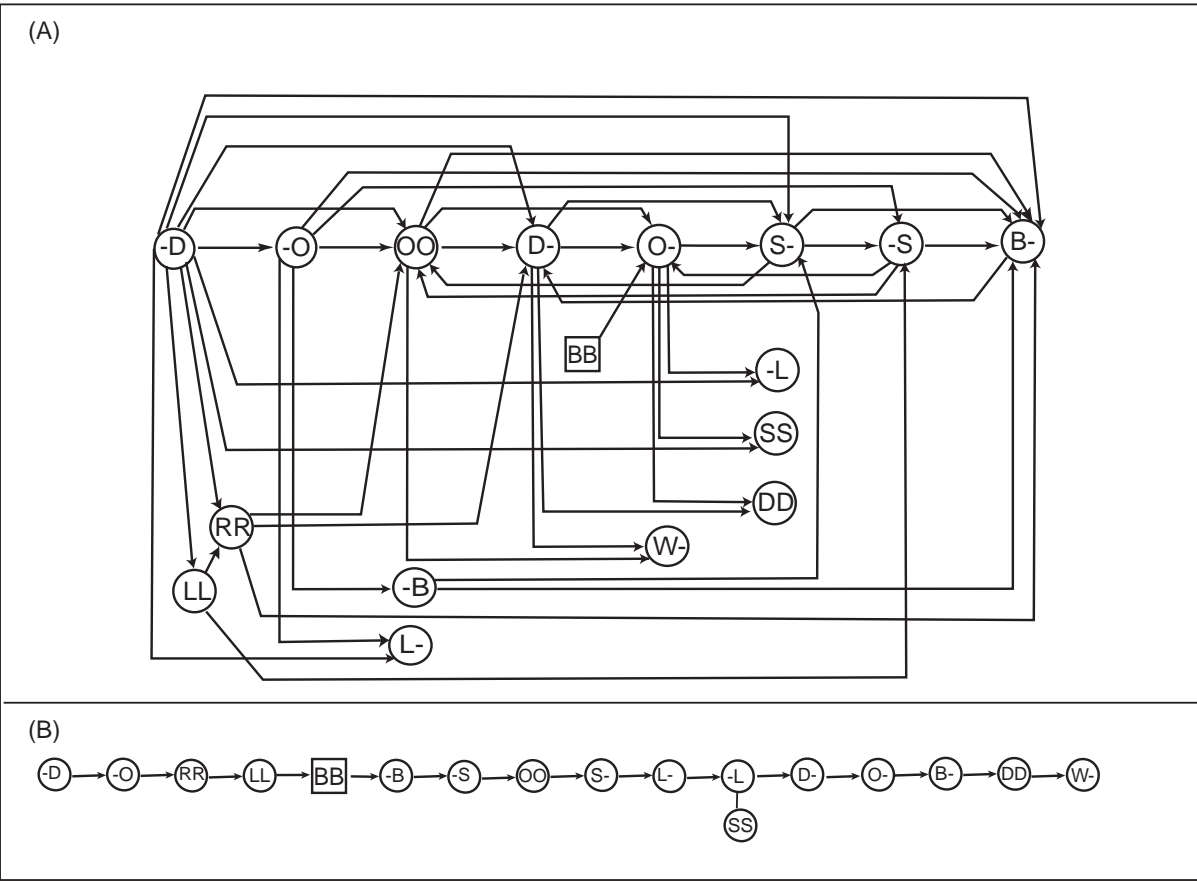

Fig. 1. - A: Dominance-subordinate network in a typical colony (V219) of R. marginata. Only individuals showing at least one instance of dominance or subordinate behaviour are shown. Each arrow represents one or more instances of dominance behaviour shown by the individual from which the arrow begins, towards the individual at which the arrow is pointed. $\mathrm{B}$ : The same individuals as in (A) are now arranged in a hierarchy, based on the index of dominance (see methods), such that the first individual at the left is the most dominant and is ranked 1. Individuals vertically aligned one below the other have tied ranks. In both (A) and (B), the queen (BB) is shown in a sqaure, rather than in a circle.

Table 1.

Numbers of wasps, numbers of dominance behaviours and DE VRIEs improved index of linearity in 12 normal colonies of $R$. marginata.

\begin{tabular}{ccccc}
\hline Nest code & \# wasps & \# DB & h' & Pr \\
\hline V213 & 64 & 281 & 0.07 & 0.14 \\
V215 & 43 & 103 & 0.1 & 0.28 \\
V217 & 59 & 167 & 0.07 & 0.28 \\
V219 & 18 & 95 & 0.22 & 0.25 \\
V220 & 25 & 49 & 0.2 & 0.23 \\
V221 & 31 & 76 & 0.13 & 0.39 \\
V221a & 14 & 61 & 0.36 & 0.15 \\
V222 & 18 & 86 & 0.34 & 0.09 \\
V223 & 31 & 107 & 0.11 & 0.33 \\
V224 & 19 & 106 & 0.24 & 0.2 \\
V224a & 7 & 15 & 0.37 & 0.58 \\
V227 & 9 & 10 & 0.37 & 0.55 \\
\hline
\end{tabular}


Table 2.

DE VRIES improved index of linearity among the top ranking 4, 5 and 6 wasps in 12 normal colonies of $R$. marginata.

\begin{tabular}{|c|c|c|c|c|c|c|}
\hline \multirow{2}{*}{$\begin{array}{l}\text { Nest } \\
\text { code }\end{array}$} & \multicolumn{2}{|c|}{ Top 4 wasps } & \multicolumn{2}{|c|}{ Top 5 wasps } & \multicolumn{2}{|c|}{ Top 6 wasps } \\
\hline & $h^{\prime}$ & $\operatorname{Pr}$ & $h^{\prime}$ & $\mathrm{Pr}$ & $h^{\prime}$ & $\operatorname{Pr}$ \\
\hline V213 & 0.6 & 0.67 & 0.6 & 0.49 & 0.43 & 0.49 \\
\hline V215 & 0.5 & 0.75 & 0.45 & 0.65 & 0.34 & 0.7 \\
\hline V217 & 0.6 & 0.68 & 0.55 & 0.55 & 0.46 & 0.55 \\
\hline V219 & 0.9 & 0.44 & 0.65 & 0.44 & 0.5 & 0.5 \\
\hline V220 & 0.6 & 0.68 & 0.55 & 0.55 & 0.46 & 0.54 \\
\hline V221 & 0.3 & 0.91 & 0.35 & 0.77 & 0.34 & 0.69 \\
\hline V221a & 0.6 & 0.67 & 0.5 & 0.61 & 0.43 & 0.58 \\
\hline V222 & 0.9 & 0.44 & 0.6 & 0.48 & 0.48 & 0.5 \\
\hline V223 & 0.7 & 0.59 & 0.55 & 0.55 & 0.63 & 0.32 \\
\hline V224 & 1.0 & 0.34 & 0.7 & 0.39 & 0.71 & 0.23 \\
\hline V224a & 0.6 & 0.67 & 0.5 & 0.59 & 0.37 & 0.58 \\
\hline V227 & 0.6 & 0.68 & 0.45 & 0.66 & 0.37 & 0.66 \\
\hline
\end{tabular}

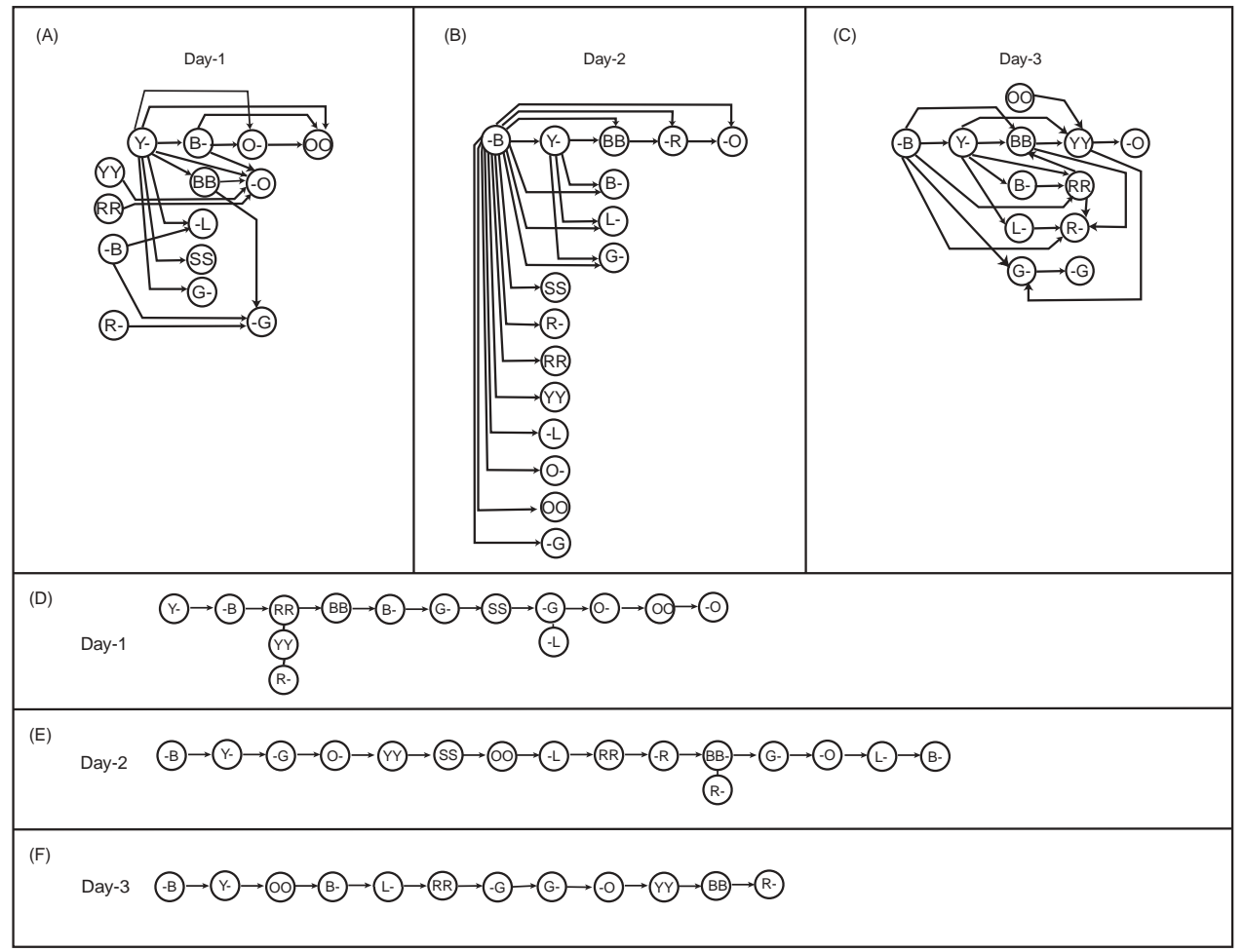

Fig. 2. - As in Fig. 1, dominance-subordinate networks (A, B, C) and dominance hierarchies (D, E, F) are shown separately for day 1 (unmanipulated colony, with queen), day 2 (without queen) and day 3 (with returned queen), for a typical colony (V248). Note that in this colony, the queen is not shown even on days 1 and 3, because she failed to participate in any dominance-subordinate behaviours. Note also, that on day 2, one individual (-B) became extremely aggressive, and is referred to as the potential queen (see text). 
Table 3

DE VRIES improved test of linearity in the presence and absence of the queen in 12 colonies of $R$. marginata. Note the very high levels of dominance on day 2, as compared to day 1 .

\begin{tabular}{|c|c|c|c|c|c|c|c|c|c|c|c|c|}
\hline \multirow[b]{2}{*}{$\begin{array}{l}\text { Nest } \\
\text { code }\end{array}$} & \multicolumn{4}{|c|}{ Day-1 (with queen ) } & \multicolumn{4}{|c|}{ Day-2 (without queen ) } & \multicolumn{4}{|c|}{ Day-3 (with queen returned) } \\
\hline & $\begin{array}{c}\# \text { of } \\
\text { wasps }\end{array}$ & $\mathrm{DB}$ & $h^{\prime}$ & $\operatorname{Pr}$ & $\begin{array}{c}\text { \# of } \\
\text { wasps }\end{array}$ & DB & $h^{\prime}$ & $\operatorname{Pr}$ & $\begin{array}{c}\# \text { of } \\
\text { wasps }\end{array}$ & DB & $h^{\prime}$ & $\operatorname{Pr}$ \\
\hline V260 & 32 & 38 & 0.13 & 0.42 & 31 & 234 & 0.23 & 0.0004 & 29 & 74 & 0.14 & 0.31 \\
\hline V270 & 25 & 22 & 0.26 & 0.37 & 24 & 109 & 0.27 & 0.02 & 19 & 19 & 0.37 & 0.21 \\
\hline V273 & 46 & 40 & 0.15 & 0.35 & 43 & 200 & 0.14 & 0.002 & 37 & 34 & 0.15 & 0.45 \\
\hline V269 & 33 & 81 & 0.11 & 0.46 & 35 & 140 & 0.16 & 0.01 & 30 & 48 & 0.15 & 0.32 \\
\hline V267 & 14 & 16 & 0.25 & 0.52 & 14 & 75 & 0.42 & 0.06 & 9 & 15 & 0.58 & 0.12 \\
\hline V262 & 13 & 19 & 0.38 & 0.28 & 14 & 90 & 0.40 & 0.05 & 12 & 41 & 0.30 & 0.29 \\
\hline V262A & 13 & 22 & 0.43 & 0.37 & 13 & 110 & 0.43 & 0.06 & 16 & 35 & 0.28 & 0.41 \\
\hline V276 & 14 & 22 & 0.22 & 0.56 & 14 & 105 & 0.42 & 0.06 & 10 & 11 & 0.57 & 0.39 \\
\hline V272 & 35 & 35 & 0.15 & 0.43 & 34 & 229 & 0.16 & 0.004 & 35 & 30 & 0.13 & 0.45 \\
\hline V268 & 33 & 58 & 0.10 & 0.41 & 33 & 148 & 0.19 & 0.03 & 33 & 55 & 0.13 & 0.46 \\
\hline V248 & 17 & 27 & 0.28 & 0.26 & 17 & 99 & 0.34 & 0.03 & 15 & 26 & 0.27 & 0.39 \\
\hline V277 & 16 & 33 & 0.23 & 0.47 & 15 & 125 & 0.35 & 0.04 & 14 & 31 & 0.34 & 0.34 \\
\hline
\end{tabular}

networks can be rather complicated. The dominance hierarchy obtained by using the index of dominance (Premnath et al. 1990) is shown in Fig. 1B. As can be seen from Fig. 1B the queen occupies rank 5 out of 18 individuals. Similar networks and hierarchies were seen in all the 12 colonies (data not shown). Using the improved test of linearity $h$ ' developed by DE VRIES (1995), we find that none of these 12 dominance hierarchies are significantly linear (Table 1 ). The $h$ ' values range from 0.07 to 0.37 and the right-tailed probabilities range from 0.09 to 0.58 . Thus dominance hierarchies in queenright colonies are not significantly linear. To examine the possibility that the hierarchy may only be linear among a few top ranking individuals, we repeated the analysis for the top ranking 4, 5 and 6 individuals respectively. Here the ranking is based on the index of dominance (PREMnath et al. 1990) as shown in Fig. 1B. However, none of these hierarchies were significantly linear, either. The $h^{\prime}$ values ranged from 0.34 to 1.0 and the right-tailed probabilities ranged from 0.09 to 0.91 (Table 2).

In experiment 2, a similar analysis was carried out separately for days 1, 2 and 3. Dominance-subordinate networks of a typical colony on days 1, 2 and 3 are shown in Fig. 2A-C. As shown in earlier studies (PREMnath et al. 1996), there is a very substantial increase in the level of aggression seen on day 2 , most of which is shown by a single individual (see below) (Fig. 2, Table 3). None of the hierarchies on day 1 (unmanipulated, with queen) and day 3 (with returned queen) were significantly linear. However on day 2 (in the absence of the queen, representing the queen determination stage, see below) the hierarchies seen in 9 out of 12 colonies were significantly linear (Table 3 ). The three colonies whose hierarchies were not classified as significantly linear were also however very close to being declared significantly linear; their right-tailed probabilities were 0.06. Even if only nine colonies (with right-tailed probability less than or equal to 0.05 ) are considered significantly linear, the proportion of colonies with significantly linear hierarchies on day $2(9 / 12)$ is significantly different from the proportion (0/12) on days 1 and 3 (G test, $P<0.05)$. It must be pointed out that, when the queen is removed, one of the workers immediately becomes extremely aggressive and begins to behave like a 
queen who is in the process of attempting to establish her status as a new queen, as described in the introduction. We refer to this individual as the potential queen (PREMnath et al. 1996, GADAGKAR 2001). If the original queen is not returned, the potential queen invariably goes on to become the next queen (GADAGKAR 2001). Thus day 2 of experiment 2 represents the queen determination stage.

\section{DISCUSSION}

$R$. marginata queens are behaviourally docile and subordinate and hence, we have previously postulated that they may use a pheromonal mechanism to suppress/regulate reproduction by their nestmates (PREMNATH et al. 1996, GADAGKAR 2001). The workers in such colonies nevertheless indulge in frequent dominancesubordinate interactions. Based on this and other evidences we have previously speculated that these dominance-subordinate interactions serve as signals by which workers regulate their own foraging rates (PREMNATH et al. 1995, GADAGKAR 2001). Since queens of $R$. marginata are very aggressive during the queen determination stage, dominance behaviour seen during this period appears to have the function of suppressing reproduction by subordinates. The finding of this study, that dominance hierarchies seen on queenright colonies are not significantly linear, and that only the hierarchies seen during the queen determination stage are significantly linear, is consistent with our speculation about the different functions of dominance-subordinate interactions in queenright colonies on the one hand and during queen determination stage on the other hand. It is reasonable to expect that dominance hierarchies are either despotic (one individual dominating all others while the rest hardly interact) or linear (with more transitive triads and few circular triads), when the function of such a hierarchy is to regulate reproductive conflicts and decide who reproduces. Similarly, it is also reasonable to expect that dominance hierarchies are less likely to be linear (with few transitive triads and more circular triads), where the function of such dominance-subordinate interactions is merely to serve as cues for regulating worker foraging.

We argue that a better understanding of the structure (e.g., linearity) and of its implications for the function of dominance hierarchies in primitively eusocial insect colonies holds much promise for understanding social organisation, both at the proximate and ultimate levels.

\section{ACKNOWLEDGEMENTS}

We thank the Department of Science and Technology, Government of India and the Ministry of Environment and Forests, Government of India for financial support.

\section{REFERENCES}

ApPLEBy M.C. 1983. The probability of linearity in hierarchies. Animal Behaviour 31: 600-608.

BeKofF M. 1977. Quantitative studies of three areas of classical ethology: social dominance, behavioral taxonomy, and behavioral variability, pp. 1-46. In: Hazlett B.A., Edit. Quantitative methods in the study of animal behavior. New York: Academic Press. 
CHANDRASHEKARA K. \& GADAGKAR R. 1991. Behavioural castes, dominance and division of labour in a primitively eusocial wasp. Ethology 87: 269-283.

CHANDRASHEKARA K. \& GADAGKAR R. 1992. Queen succession in the primitively eusocial tropical wasp Ropalidia marginata (Lep.) (Hymenoptera: Vespidae). Journal of Insect Behaviour 5: 193-209.

CHASE I.D. 1974. Models of hierarchy formation in animal societies. Behavioral Science 19: 374-382.

Clutton-Brock T.H., Albon S.D., Gibson R.M. \& Guinness F.E. 1979. The logical stag: adaptive aspects of fighting in Red Deer (Cervus elaphus L.). Animal Behaviour 27: 211-225.

DE VRIES H. 1995. An improved test of linearity in dominance hierarchies containing unknown or tied relationships. Animal Behaviour 50: 1375-1389.

Gadagkar R. 1991. Belonogaster, Mischocyttarus, Parapolybia, and independent founding Ropalidia, pp. 149-190. In: Ross K.G. \& Matthews R.W., Edits. The social biology of wasps. Ithaca, London: Cornell University Press.

GADAGKAR R. 2001. The social biology of Ropalidia marginata: towards understanding the evolution of eusociality. Cambridge, Massachusetts: Harvard University Press.

GADAGKAR R. \& Joshi N.V. 1983. Quantitative ethology of social wasps: time-activity budgets and caste differentiation in Ropalidia marginata (Lep.) (Hymenoptera:Vespidae). Animal Behaviour 31: 26-31.

Gamboa G.J., Wacker T.L., Scope J.A., Cornell T.J. \& Shellman-Reeve J. 1990. The mechanism of queen regulation of foraging by workers in paper wasps (Polistes fuscatus, Hymenoptera,Vespidae). Ethology 85: 335-343.

JEANNE R.L. 1972. Social biology of the neotropical wasp Mischocyttarus drewseni. Bulletin of the Museum of Comparative Zoology 144: 63-150.

KASUYA E. 1995. A randomization test for linearity of dominance hierarchies. Journal of Ethology 13: 137-140.

LANDAU H.G. 1951. On dominance relations and the structure of animal societies: I. Effect of inherent characteristics. Bulletin of Mathematical Biophysics 13: 1-19.

Lehner P.N. 1996. Handbook of ethological methods. Cambridge: Cambridge University Press.

PARdi L. 1948. Dominance order in Polistes wasps. Physiological Zoölogy 21: 1-13.

Premnath S., Chandrashekara K., Chandran S. \& Gadagkar R. 1990. Constructing dominance hierarchies in a primitively eusocial wasp, p. 80. In: Veeresh G.K. et al., Edits. Social insects and the environment. Proceedings of the 11th International Congress of IUSSI. New Delhi: Oxford \& IBH Publishing Co. Pvt. Ltd.

Premnath S., Sinha A. \& Gadagkar R. 1995. Regulation of worker activity in a primitively eusocial wasp, Ropalidia marginata. Behavioral Ecology 6: 117-123.

Premnath S., Sinha A. \& Gadagkar R. 1996. Dominance relationships in the establishment of reproductive division of labour in a primitively eusocial wasp (Ropalidia marginata). Behavioral Ecology and Sociobiology 39: 125-132.

Reeve H.K. 1991. Polistes, pp. 99-148. In: Ross K.G. \& Matthews R.W., Edits. The social biology of wasps. Ithaca, London: Cornell University Press.

ReEve H.K. \& GAMBOA G.J. 1983. Colony activity integration in primitively eusocial wasps: the role of the queen (Polistes fuscatus, Hymenoptera: Vespidae). Behavioral Ecology and Sociobiology 13: 63-74.

ReEve H.K. \& GAmBoA G.J. 1987. Queen regulation of worker foraging in paper wasps: a social feedback control system (Polistes fuscatus, Hymenoptera: Vespidae). Behaviour 102: $147-167$.

Tindo M. \& DeJEan A. 2000. Dominance hierarchy in colonies of Belonogaster juncea juncea (Vespidae, Polistinae). Insectes Sociaux 47: 158-163.

West-Eberhard M.J. 1969. The social biology of polistine wasps. Miscellaneous Publications, Museum of Zoology University of Michigan 140: 1-101. 